\title{
Validation of the "Quality of Life in School" instrument in Canadian elementary school students
}

Satvinder Ghotra, Jessie-Lee D Mclsaac, Sara FL Kirk, Stefan Kuhle

Background: School is an integral component of the life of a child and thus, quality of school life is an important part of the overall quality of life experienced by a child. There are a few instruments available to measure the quality of school life but they are often not available in English, or they are not appropriate for use alongside with other instruments in a survey of young children. The Quality of Life in School (QoLS) instrument is a short selfreport measure to assess elementary school students' perception of their quality of school life in four domains. The instrument was developed in Israel and has been validated among Hebrew-speaking children. The aim of the current study was to evaluate the psychometric properties of the QoLS measure in Canadian elementary school children. Methods: 629 children attending grades 4 to 6 were recruited in a population-based cross-sectional study. The QoLS measure was administered to participating children by trained research assistants. In addition, their socio-demographic details and academic data were also obtained. The psychometric testing included exploratory factor analysis and reliability estimation using internal consistency (Cronbach's Alpha). Construct validity was investigated using the known groups comparisons for discriminative validity and via convergent validity. Results: A four-factor structure was generated explaining $39 \%$ of the total variance in the model. The results showed good internal consistency and acceptable floor and ceiling effects. Cronbach's Alpha ranged from 0.75 to 0.93 . Known groups comparisons showed that the QoLS measure discriminated well between subgroups on the basis of gender, grade, and academic achievement, thus providing evidence of construct validity. The convergent validity was also appropriate with all the four domains demonstrating moderate to strong correlations to each other and to the total QoLS score. Conclusions: QoLS appears to be a valid and reliable measure for quality of school life assessment in young Canadian children. 
1 Validation of the "Quality of Life in School" instrument in Canadian elementary school

2 students

3

4 Satvinder Ghotra, MD, MSc

5 Dept. of Pediatrics, Division of Neonatal-Perinatal Medicine, Dalhousie University, Halifax, NS,

6 Canada

7

8 Jessie-Lee Dawn McIsaac, PhD

9 Applied Research Collaborations for Health, School of Health and Human Performance,

10 Dalhousie University, Halifax, NS, Canada

11

12 Sara F.L. Kirk, PhD

13 Applied Research Collaborations for Health, School of Health and Human Performance,

14 Dalhousie University, Halifax, NS, Canada.

15

16 Stefan Kuhle, $\mathrm{MD}, \mathrm{PhD}$ (corresponding author)

17 Perinatal Epidemiology Research Unit, Depts of Pediatrics and Obstetrics \& Gynaecology,

18 Dalhousie University, Halifax, NS, Canada.

19

20 Corresponding author:

21 Dr. Stefan Kuhle, Perinatal Epidemiology Research Unit, IWK Health Centre, 5980 University

22 Avenue, Halifax, NS B3K 6R8, Canada

23 Phone: +1 (902) 470-3731 
24 Email: stefan.kuhle@dal.ca

25 


\section{ABSTRACT}

27 Background: School is an integral component of the life of a child and thus, quality of school

life is an important part of the overall quality of life experienced by a child. There are a few instruments available to measure the quality of school life but they are often not available in English, or they are not appropriate for use alongside with other instruments in a survey of young children. The Quality of Life in School (QoLS) instrument is a short self-report measure to assess elementary school students' perception of their quality of school life in four domains. The instrument was developed in Israel and has been validated among Hebrew-speaking children.

34 The aim of the current study was to evaluate the psychometric properties of the QoLS measure in

35 Canadian elementary school children.

36 Methods: 629 children attending grades 4 to 6 were recruited in a population-based cross-

37 sectional study. The QoLS measure was administered to participating children by trained research assistants. In addition, their socio-demographic details and academic data were also obtained. The psychometric testing included exploratory factor analysis and reliability estimation using internal consistency (Cronbach's Alpha). Construct validity was investigated using the

41 known groups comparisons for discriminative validity and via convergent validity.

42 Results: A four-factor structure was generated explaining 39\% of the total variance in the model.

43 The results showed good internal consistency and acceptable floor and ceiling effects.

44 Cronbach's Alpha ranged from 0.75 to 0.93 . Known groups comparisons showed that the QoLS

45 measure discriminated well between subgroups on the basis of gender, grade, and academic

46 achievement, thus providing evidence of construct validity. The convergent validity was also

47 appropriate with all the four domains demonstrating moderate to strong correlations to each other 48 and to the total QoLS score. 
49 Conclusions: QoLS appears to be a valid and reliable measure for quality of school life

50 assessment in young Canadian children.

51 Keywords: quality of life; children; school; Canada 


\section{INTRODUCTION}

53 Quality of life has been acknowledged as an important and relevant concept for people of all 54 ages including school-aged children. In children, the concept of quality of life arises from a 55 dynamic interaction of several variables including child, family, environment and school. Of

56 these, school is an integral component of the life of a child and thus, quality of school life is an

57 important part of the overall quality of life experienced by a child. Quality of school life could be 58 defined as well-being resulting from children's integration into the life and the environment of

59 their schools (1) and represents the degree of satisfaction or dissatisfaction perceived by children

60 with their school life (2). Quality of school life has been conceived as an important aspect of

61 schooling by numerous authors since it is associated with students' academic motivation and

62 performance (3-7). Quality of school life can be viewed as a measure of students' attitude and

63 feelings towards school, which in turn is positively associated with their intentions to continue at $64 \operatorname{school}(8)$.

Various factors may potentially influence quality of school life, such as the age and gender of

67 students. The literature on gender influences on quality of school life has shown conflicting results. Many studies reported that girls perceive a better quality of school life compared to boys $(4,9-12)$, while others found no differences between the genders $(13,14)$. However, the effect sizes in some of the studies that found significant gender differences were often very small $(<0.2$ standard deviations $)(4,10)$ or the gender differences were not consistently found for all domains of an instrument (10). The reasons for the higher perceived quality of school life in girls may be a

73 better match of the female gender role with school expectations (15). Girls also appear to have a more positive view of teacher support and the school environment (16). By contrast to gender, 
75 there is consensus in the literature that age is an important determinant of quality of school life

76 with younger students perceiving their quality of school life higher than their older peers $(12,14-$

77 17). With increasing age in childhood and adolescence, life satisfaction decreases across all areas

78 (i.e. family, friends, school, living environment) (17).

In Canada, $98 \%$ of children are in the school system for almost half their waking hours and 81 schooling is compulsory from age five to sixteen (with minor variations dependent on the 82 province/territory). The Health Behaviour in School-aged Children (HBSC) is a cross-national 83 survey of school students that collects data every four years on students' health and well-being, social environments and health behaviours (18). The survey includes several items related to quality of school life, including feelings of school satisfaction, belonging and safety and perceptions of teachers and peers. Although a only minority of students reported liking school a

87 lot, the majority of students reported that they felt they belonged at their school. The HBSC results in Canada are similar to the international results previously reported with differences reported across gender and age (e.g., students' positive perceptions of teachers decreased with grade level with girls being more likely to report positive perceptions) (19).

92 There are a number of tools available for quality of school life assessment in young children but many of them are not available in English, do not cover all domains of quality of school life, or

94 are impractical for use in a research study $(6,10,11,14,20-22)$. The majority of research on 95 quality of school life and student well-being instruments has been published in the education 96 research literature, which may make the instruments less accessible to health researchers. The 97 School Well-Being Profile was developed and validated for Finnish school children in grades 4 to 
9812 as a tool to help schools evaluate well-being of their students (10, 16, 23); an English

99 translation is available. The instrument consists of 56 (elementary school) and 80 (high school)

100 questions, respectively, in four domains (school conditions, social relationships, self-fulfillment,

101 health). Administration of the School Well-Being Profile is web-based and the tool has been

102 tested and used in a number of settings but to the best of our knowledge is used mostly for school

103 health evaluations, and less for academic research. Its computer-based mode of administration

104 may make it impractical to use in an otherwise paper-based research survey. Also, the large

105 number of items in the School Well-Being Profile may place too large a burden on younger

106 students, especially if the measure is used alongside other measures in a comprehensive survey.

107 The Quality of School Life (QSL) scale based on the work of Williams and Batten (24) and

108 others $(25,26)$ was designed to measure the well-being of Australian high school students but

109 there is no simplified version for elementary school students. Murray-Harvey developed an 86-

110 item Your Life at School questionnaire with five domains (supportive relationships, stressful

111 relationships, psychological health, social/emotional adjustment, academic performance) and

112 validated it in Australian school children in grades 5 to 9 (6). In the Netherlands, Opdenakker

113 and van Damme (20) constructed a well-being scale consisting of eight indicators (Well-being at

114 school, Social integration in the class, Relationship with teachers, Interest in learning tasks,

115 Motivation towards learning tasks, Attitude to homework, Attentiveness in the classroom, and

116 Academic self-concept) based on an earlier school well-being measure (27). Unfortunately, this

117 instrument and most of the publications on them are only available in Dutch. Lohre et al.

118 developed a set of 49 Likert-type and open-ended questions that examine academic success, peer

119 and teacher relationships, and support in school but not the school environment (11). The

120 questionnaire was tested in 423 students in grades 1 to 10 in Norway and showed acceptable test- 
121 retest reliability. However, instrument structure, internal consistency, and validity were not

122 formally tested. The Quality of Life in School (QoLS) instrument is a self-report measure

123 developed in Israel to assess elementary school students' perception of their quality of school life

124 (14). The QoLS scale is a paper-based instrument that assesses all relevant domains of students'

125 well-being in school including the school environment, while still being brief enough (37 items)

126 to be used with other instruments in a comprehensive survey of young children. For these

127 reasons, we felt that the QoLS instrument was most suitable measure to assess quality of school

128 life and the impact of interventions improving student health and well-being in our study of

129 elementary school children in Canada.

131 The QoLS instrument is constructed based on the theoretical definition of quality of school life 132 described by Malin and Linnakyla (9), and the biopsychosocial model (28). As per Malin and

133 Linnakyla's definition, quality of school life is "students' general well-being and satisfaction,

134 from the point of view of their positive and negative experiences, particularly in activities typical

135 of school". The biopsychosocial model places an individual's relationships and activities in the

136 context of their environment. Therefore, an instrument that is based on these two frameworks

137 should not only examine the students' wellbeing at school but also their relationships with their

138 peers and teachers, as well as the school's physical environment and activities. Items for the

139 instrument were developed from the theoretical literature on quality of school life and from semi-

140 structured interviews with students, parents, and teachers. The QoLS instrument has

141 multidimensional structure consisting of four factors: teacher-student relationship and school

142 activities, physical environment, negative feelings toward school, and positive feelings toward

143 school (14). The framework of the QoLS differs from that of the School Well-Being Profile, a 
144 well-researched and frequently used measure of QSL developed in Finland $(10,16,23)$. The

145 School Well-Being Profile is grounded in Allardt's model of well-being (29), which views well-

146 being as a state that allows an individual to satisfy their basic needs. The model uses three

147 indicator categories for an individual's needs: having, loving, and being. The developers of the

148 School Well-Being Profile applied this model to students in schools and defined well-being in

149 school as a four-dimensional construct with the domains school conditions (having), social

150 relationships (loving), means for self-fulfillment (being), and health status (health) (16). While

151 the underlying framework may differ between the School Well-Being Profile and the QoLS scale,

152 there are a lot of communalities, and both instruments assess the concepts environment,

153 relationships, attitude, and health, albeit partly in different domains. The QSL scale, originally

154 developed by Williams and Batten (24), is based on society level imperatives of schooling

155 (adaptation, goal attainment, integration, and latency) that were translated to the corresponding

156 student experiences of schooling (opportunity to learn, relevance or utility of schooling,

157 identification with the student role, and perception of own status as student). The instrument has

158 been refined over the years by a number of researchers $(25,26)$, and the latter four categories

159 along with a measure of the perception of teachers and two affective outcomes now form the

160 seven subscales of the instrument (General affect, Negative affect, Status, Identity, Teachers,

161 Opportunity, Achievement) (4). There is some overlap in the items and domains with both the

162 QoLS scale and the School Well-Being Profile but the most notable difference is the absence of

163 the assessment of the school environment in the QSL instrument.

164 Since the QoLS instrument has not yet been validated in Canadian students, the objective of this

165 study was to determine the reliability and validity of the measure in a sample of elementary

166 school students attending grades 4 to 6 in the Canadian province of Nova Scotia. 


\section{MATERIALS \& METHODS}

169 A cross-sectional population-based study was conducted in spring 2014 to evaluate school health

170 practices and student health and health behaviours in the Tri-County Regional School Board

171 (TCRSB), Nova Scotia, Canada. The TCRSB is a rural school board located at the South-

172 Western tip of Nova Scotia that encompasses the three counties of Shelburne, Yarmouth, and

173 Digby. The Board serves approximately 6400 students in 27 schools in an area of over 7,000

174 square kilometers. All schools and students attending grade 4-6 (age 9-12 years) in the school

175 board were invited to participate. The trained research assistants visited these schools and

176 provided all eligible students with the study packages encompassing parental consent forms and

177 a parental survey. Parents were requested to complete these at home and deliver them back to

178 school. Research assistants visited the schools again to gather the parental information and

179 students were invited to complete the QoLS questionnaire. To ensure a uniform assessment and

180 to prevent any bias, the research assistants were trained to administer the survey. Ethics approval

181 for this study was obtained from the Health Research Ethics Boards at the Dalhousie University

182 (Protocol \# 2013-3094). The permission for data collection was also granted from the

183 participating school board and individual schools. Written informed consent was obtained from

184 the parents of all children included in the study.

185 All 18 eligible schools the school board agreed to participate. A total of 1445 students and their

186 parents were invited to participate, of whom 670 responded resulting in a response rate of $46 \%$.

187 The student survey was filled out by 636 students; of these $18 \%$ had missing responses for less

188 than four of the 37 questions, and only seven students (1\%) had four or more missing responses

189 and were removed from the analysis, resulting in a final sample size of 629. Parental consent to 
190 link the study information with academic performance data was obtained for 565 students. Non-

191 response appeared to be largely driven by competing priorities in schools that resulted in non-

192 compliance of teachers in reminding students to return their consent forms. Determination of

193 response rates by area-level income decile based on Census of Canada information did not

194 indicate a strong relationship of non-response with household income.

195

196 QoLS questionnaire

197 The QoLS questionnaire is a self-report measure of students' quality of school life developed in

198 the Hebrew language (14). The measure consists of 36 items organized into 4 domains: teacherstudent relationship and social activities (12 items), physical environment (11 items), negative

200 feelings towards school (8 items) and positive feelings towards school (5 items). The participants 201 respond on a 4-point Likert scale (from "never true" to "always true"). Each item is scored on a

202 scale from 1 to 4 with negative items being reverse scored. The instrument provides four domain 203 scores and a total QoLS score, with higher scores indicating better quality of school life. The 204 scale has been demonstrated to be reliable and valid in Hebrew-speaking elementary school age 205 children in Israel (14). The current study used the English translation (by its creators) of the 206 QoLS with some minor changes to the wording of some of the items (by the authors), e.g.

207 "whiteboard" instead of "blackboard", or "walk/bike/ride to school" instead of "way to school";

208 the English version used contained an additional item (classroom lighting) that was later dropped 209 from the Hebrew version of the scale. Completion of the scale questions by the students took 210 about ten minutes.

\section{Socio-demographic information}


213 The parent survey contained questions on socio-demographic factors such as household income

214 (4 levels: $\$ 0$ to $\$ 40,000 ; \$ 40,001$ to $\$ 60,000 ; \$ 60,001$ to $\$ 100,000 ;>\$ 100,000 \mathrm{CDN}$ ), parental

215 education (secondary school or less, college, or university), and area of residence (urban vs.

216 rural; based on postal code). In addition, parents also reported their child's health as perceived by

217 themselves (excellent, very good, good, or poor).

218

219 Academic performance data

220 The academic performance for Mathematics and English Language Arts (ELA) was also

221 collected for the 2013/14 school year for all students. Grades were obtained directly from the

222 school board for each of the three terms. Grades (ranging from "A" to "D") were transformed to

223 a numeric scale (1 to 4 ), and the median of the three terms was used as the overall grade estimate

224 for the academic year.

226 Statistical analysis

227 Descriptive statistics were presented as relative frequencies or means and standard deviations as

228 applicable. Missing QoLS information for students with $\leq 3$ missing responses was imputed

229 using hot deck imputation. Hot deck imputation imputes missing values using non-missing

230 information from randomly selected, similar (here: students in the same school) observations in

231 the same dataset. Scoring of the measure was performed using the standard scoring instructions

232 with negative items being reverse scored. A mean score was computed for all the domains and 233 total QoLS score.

234 Because the QoLS instrument was applied in a culturally different context and in another

235 language, we decided to perform an exploratory factor analysis (with varimax rotation) rather 
236 than a confirmatory factor analysis to examine the multidimensional structure of the instrument.

237 The factor analysis was based on a polychoric correlation matrix of the item responses.

238 Eigenvalues, scree plot, and parallel analysis were used to determine the number of factors to

239 retain (30). Factor loadings of $\geq 0.30$ were used to allocate items to a scale. Items that loaded on

240 more than one factor were assigned to the factor with the higher loading. Content validity of the

241 QoLS was presumed to be appropriate. Internal consistency reliability for the entire

242 questionnaire and each domain was assessed using Cronbach's Alpha with values between 0.70

243 and 0.95 considered acceptable.

244 Construct validity was examined using several a priori hypotheses for discriminative and

245 convergent properties of the instrument. Children's QoLS scores were expected to differ by (1)

246 gender (girls will report higher scores than boys), (2) school grade (grade 4 students will

247 perceive higher scores than grade 5 or 6 students), (3) parent report of child's health status

248 (children with better health status will have a higher scores) and (4) academic ranking (children

249 with better academic grades will have higher scores). Comparison between these known groups

250 was performed using t-test or ANOVA as applicable. Convergent validity was assessed using

251 Pearson's correlations among different subscales and the overall scale. We hypothesized

252 moderate ( $r=0.40$ to 0.59$)$ to strong $(r>0.60)$ correlations between different subscales of QoLS

253 and to the total QoLS, as they measure the same construct. Floor and ceiling effects were

254 considered to be present when more than $15 \%$ of the students obtained the lowest or the highest

255 possible scores. The significance level was set at $\mathrm{p}<0.05$. The analysis was performed using $\mathrm{R}$

2563.1 (31) with the psych package (32).

257

258 RESULTS 
259 The socio-demographic characteristics of the 629 children are presented in Table 1 . The

260 distribution of students among the three grade levels was fairly even. About two-thirds of

261 students resided in urban areas, 31\% came from households with an annual household income $\leq$

$262 \$ 60,000$ (median total household income in Canada in 2013: \$76,550), and 26\% of parents and

263 caregivers had secondary school education or less.

264 The responses to the individual scale questions are shown in Figure 1. Eigenvalues, scree plot, 265 and parallel analysis suggested the presence of four factors: Psychosocial (PS) (eigenvalue:

266 4.34); Attitude towards school (AT) (eigenvalue: 3.67); School environment (SE) (eigenvalue:

267 3.12); and Teacher-student relationship (TS) (eigenvalue: 3.12). Item loadings are shown in

268 Table 2 and Figure 2. There were 34 items in the final scale with 12, 8, 8 and 6 items in PS, AT,

269 SE and TS factors respectively. Three items (trip to school, lighting in classroom, social

270 activities at school) did not load on any of the factors and were dropped. The 4-factor structure

271 explained $39 \%$ of the total variance in the model. The mean scale scores and other scale

272 characteristics are shown in Table 3. Cronbach's Alpha ranged from 0.75 to 0.93 for the

273 domains. Floor and ceiling effects were $0 \%$ for the total QoLS score.

274 Discriminative properties of the instrument are listed in Table 4. The mean QoLS scores differed

275 by gender with girls reporting having higher scores than boys. The difference was statistically

276 significant in all except the overall score $(P=0.061)$ and the PS domain. Quality of school life

277 also differed by grade with grade 4 students demonstrating significantly higher scores than grade

2785 and 6 students in multiple domains. Students achieving higher academic grades had

279 significantly higher scores in all domains of QoLS measure. By contrast, students' quality of

280 school life did not differ significantly by parent report of child's health status except in the PA 
281 domain. Correlations between different domains of the instrument were moderate to strong (all $P$

$282<0.0001)($ Table 5). All four domains strongly correlated with the total QoLS score.

283

284 DISCUSSION

285 Our study assessed the psychometric properties of the QoLS measure in Canadian elementary

286 school children and provided some evidence in favour of its reliability and construct validity.

287 The study findings indicate that the QoLS tool is an acceptable and psychometrically robust

288 measure to assess quality of school life in young Canadian school aged children attending grade

2894 to 6 (aged around 9 to 12 years). The study findings also suggest that the QoLS measure is

290 potentially suitable for inclusion in large-scale surveys to assess quality of school life in

291 elementary school students.

292

293 The factor analysis yielded four subscales (psychosocial, attitude towards school, school

294 environment and teacher-student relationship) that are similar but not identical to the four

295 subscales reported for the original QoLS measure. Weintraub and Erez' Negative feelings toward

296 school category appears to correspond to the Psychosocial domain from our analysis. The

297 remaining three categories (Teacher-student relationship and school activities, Physical

298 environment, Positive feelings toward school) were similar to the ones found in our study but the

299 number of items in each of the four factors differed from the original publication: While

300 Weintraub and Erez reported 8, 5, 11, and 12 items, respectively, in the Negative feelings

301 towards school, Positive feelings towards school, Physical environment, and Teacher-student

302 relationship and social activities, we found 12, 8, 8 and 6 items in the corresponding subscales

303 (two items were dropped because of loadings $<0.30$ ). Since the authors did not publish the 
304 detailed results from their factor analysis we can only speculate that these differences are related

305 to the different cultural contexts that the instrument was used in the two studies. Despite these

306 differences, the structure of the QoLS as determined in this study is consistent with the

307 theoretical framework underlying the QoLS, and in a broader sense also with that of the School

308 Well-Being Profile, which covers similar domains as discussed in the Introduction $(10,14,16)$.

309 Future studies in the Canadian context should use the shortened 34-item version with the revised

310 4-factor structure (Table 2) developed in the current study. The 4-factor structure explained 39\%

311 of the variance in our sample of young Canadian students, which is less than the variance

312 reported in the original publication (51\%) (14). The different amount of variance explained by

313 the model may be related to the fact that the finding is from the analysis of the pre-final version

314 of the QoLS scale, which used 40 items. The percentage variance explained was not reported for

315 the factor structure of the School Well-Being Profile $(10,23)$ or any of the other quality of school

316 life scales.

317

318 The hypothesis regarding the subscale correlations also showed acceptable results. All four

319 factors had moderate to strong significant correlations with each other and with the total score

320 lending support to its good convergent validity. The results are also in accordance with the

321 previous research and support the fact that each of the QoLS factors contributes to the

322 measurement of the quality of life construct at school. Of note, Weintraub and Erez found a

323 (weak) negative correlation of the Negative feelings towards school factor with both the Physical

324 environment and Teacher-student relationship factor, which indicated that the students with

325 worse feelings about themselves and their school perceived better physical environment and

326 teacher student relationship (14). These observations were hard to justify. By contrast, our study 
327 demonstrated no negative correlations amongst different factors imparting support to the

328 convergent validity of the instrument.

330 The psychometric analysis of the QoLS measure showed desirable results. The scale was found

331 to be acceptable on the tested sample of students since the number of missing item responses was

332 low and the time spent completing the questions was brief. The internal consistency overall and

333 for the QoLS subscales was excellent. The results of known-group comparison demonstrated that

334 the QoLS was sufficiently sensitive to discriminate between different subgroups by gender,

335 grade and academic performance, in accordance with our a priori hypotheses for the measure.

336 Girls had higher scores than boys with the exception of the Psychosocial subscale. Konu and

337 Lintonen also found higher scores among girls across all domains of the School Well-Being

338 Profile except Health status, which is similar in scope to the "Psychosocial" subscale in the

339 QoLS $(10,16)$. The effect sizes for the gender differences in QoLS scores were fairly small,

340 which is in keeping with existing literature (4, 9-12). The decrease of the QoLS score with age is

341 also well described in the literature $(12,14-17)$. The largest effects were seen in the Teacher-

342 student relationship and School environment subscale but surprisingly there was no change in the

343 Attitude towards school subscale. We also found very strong positive associations of academic

344 performance with QoLS scores with effect sizes of up to 0.6 standard deviation units. This

345 association has been described before by others $(4,6)$ but due to the cross-sectional design of

346 those studies and the present one, no statement is possible about directionality of the association.

347 Overall and subscale scores for the QoLS increased with parent-reported health status but the

348 differences were only significant for the Attitude towards school subscale but not for the

349 Psychosocial subscale, which contains a number of health-related items. Possibly, the parents' 
350 assessment of their child's health status was more reflective of physical and mental health

351 problems that require medical attention, while the Psychosocial subscale captured subclinical

352 problems that the parents may not be aware of.

353

354 The concept of quality of school life also closely relates to the health promoting schools (HPS)

355 approach $(33,34)$. HPS is an internationally recognized framework for supporting improvements

356 in students' educational outcomes while addressing school health in a planned, integrated and

357 holistic way. Similarly, the quality of school life approach also intends to assess the students'

358 health, educational and social outcomes in an integrated fashion that encompasses different

359 aspects of school environment. Hence, the QoLS instrument or other measures of quality of

360 school life may be used to evaluate outcomes of HPS interventions, which have documented

361 challenges with outcome assessment due to its varied implementation in different schools or

362 settings $(35,36)$. In fact, some items on the School environment and Teacher-student

363 relationship domains of the QoLS instrument align with the environmental and curriculum

364 domain of HPS but further research is needed to examine use of the QoLS tool in such a setting.

365 The sensitivity of the instrument in picking up differences in gender, age, and academic

366 performance needs to be taken into account when QoLS scores are compared e.g. between

367 schools with and without an HPS program as such differences may lead to a spurious estimates

368 of the effect of an intervention.

370 The limitations of the study included an inability to perform test-retest reliability and test

371 responsiveness of the scale due to the cross sectional nature of the study design. However, the

372 floor and ceiling effects were computed and found to be acceptable except for the teacher- 
373 students relationship domain, which had significant ceiling effect. These findings may have

374 considerable implications for the planning and evaluation of effectiveness of the school

375 interventions. Another limitation may be the study setting in a rural, socioeconomically

376 disadvantaged region of Canada, which may not be representative of more urban areas. Strengths

377 of our study include a population-based study design and the availability of academic

378 performance and socio-demographic information on the participants, which allowed for known

379 groups comparisons.

380

381 CONCLUSIONS

382 Our study has demonstrated that the QoLS scale is a reliable and valid tool for quality of school

383 life assessment in Canadian elementary school children. Quality of school life is positively

384 associated with academic performance in elementary school students. Future studies in the

385 Canadian context should use the shortened 34-item version with the revised 4-factor structure

386 developed in the current study. The QoLS scale may be used as a student-level outcome in the

387 evaluation of HPS interventions but more research is needed to evaluate the instrument in that

388 context.

389 


\section{REFERENCES}

391 1. Karatzias P, Papadioti V, Power K, Swanson V. Quality of school life. A cross-cultural

392 study of Greek and Scottish secondary school pupils. Eur J Educ 2001; 36: 91-105.

393 2. Epstein JL, McPartland JM. The concept and measurement of the quality of school life. Am 394 Educ Res J 1976; 13: 15-30.

395 3. Karatzias A, Power KG, Swanson V. Quality of school life: Development and preliminary 396 standardization of an instrument based on performance indicators in Scottish secondary 397 schools. School Eff School Improv 2001; 12: 265-284.

398 4. Mok MC, Flynn M. Determinants of students' quality of school life: A path model. Learn $399 \quad$ Environ Res 2002; 5: 275-300.

400 5. Goodenow C, Grady KE. The Relationship of School Belonging and Friends' Values to $401 \quad$ Academic Motivation Among Urban Adolescent Students. J Exp Educ 1993; 62: 60-71.

402 6. Murray-Harvey R. Relationship influences on students' academic achievement, 403 psychological health and well-being at school. Educ Child Psychol 2010; 27: 104-115.

404 7. Wang M, Holcombe R. Adolescents' perceptions of school environment, engagement, and 405 academic achievement in middle School. Am Educ Res J 2010; 47: 633-662.

406 8. Ainley J, Foreman J, Sheret M. High School Factors That Influence Students to Remain in 407 School. J Educ Res 1991; 85: 69-80.

408 9. Malin A, Linnakyla P. Multilevel modeling in repeated measures of the quality of Finnish $409 \quad$ school life. Scand J Educ Res 2001; 45: 145-166.

410 10. Konu AI, Lintonen T. School well-being in Grades 4-12. Health Educ Res 2006; 21: 633$411 \quad 642$.

412 11. Løhre A, Kvande MN, Hjemdal O, Lillefjell M. A two-year perspective: who may ease the 
413 burden of girls' loneliness in school. Child Adolesc Psychiatry Ment Health 2014; 8: 10.

414 12. Kong CK. Classroom Learning Experiences and Students' Perceptions of Quality of School

$415 \quad$ Life. Learn Environ Res 2008; 11: 111-129.

416 13. Gillman R, Huebner ES. Characteristics of adolescents who report very high life

417 satisfaction. J Youth Adolesc 2006; 35: 311-319.

418 14. Weintraub N, Bar-Haim Erez A. Quality of Life in School (QoLS) questionnaire:

419 development and validity. Am J Occup Ther 2009; 63: 724-731.

420 15. Samdal O, Nutbeam D, Wold B, Kannas L. Achieving health and educational goals through

421 schools - a study of the importance of the school climate and the students' satisfaction with

422 school. Health Educ Res 1998; 13: 383-397.

423 16. Konu A, Lintonen T. Theory-based survey analysis of well-being in secondary schools in 424 Finland. Health Promot Int 2006; 21: 27-36.

425 17. Park N. Life Satisfaction Among Korean Children and Youth. School Psychol Int 2005; 26:

$426 \quad 209-223$.

427 18. HBSC International Coordinating Centre. Health Behaviour in School-aged Children -

428 World Health Organization Collaborative Cross-National Survey [Internet]. [cited 2015

429 Nov 23]. Available from: http://www.hbsc.org/about/index.html

430 19. Freeman JG, King M, Pickett W. The health of Canada's young people: a mental health

431 focus. Ottawa: Public Health Agency of Canada; 2011.

432 20. Opdenakker MC, Van Damme J. Effects of Schools, Teaching Staff and Classes on

433 Achievement and Well-Being in Secondary Education: Similarities and Differences

$434 \quad$ Between School Outcomes. School Eff School Improv 2000; 11: 165-196.

435 21. Sari M. Assessment of school life: reliability and validity of Quality Of School Life scale. 
$436 \quad$ Hacettepe University J Educ 2012; 42: 344-355.

437 22. Rauer W, Schuck KD. Fragebogen zur Erfassung emotionaler und sozialer

438 Schulerfahrungen von Grundschulkindern erster und zweiter Klassen (FEESS 1-2).

439 Handanweisung. Göttingen: Beltz Test GmbH; 2004.

440 23. Konu A, Alanen E, Lintonen T, Rimpelä M. Factor structure of the School Well-being

$441 \quad$ Model. Health Educ Res 2002; 17: 732-742.

442 24. Williams T, Batten M. The quality of school life. Melbourne, Australia: Australian Council 443 for Educational Research; 1981.

444 25. Ainley J, Bourke S. Student views of primary schooling. Res Papers Educ Policy Practice $445 \quad 1992 ; 7: 107-128$.

446 26. Mok M. Construct validity of the Quality of School Life scale. Psychol Test Bull 1992; 5: $447 \quad 47-51$.

448 27. Stoel WGR, Pijl YJ. De relatie tussen de grootte van scholen voor voortgezet onderwijs en 449 het welbevinden van de leerlingen. Haren: Research instituut voor het onderwijs in het $450 \quad$ Noorden; 1980.

451 28. Engel GL. The need for a new medical model: a challenge for biomedicine. Science 1977;

452 196: 129-136.

29. Allardt E. Dimensions of welfare in a Comparative Scandinavian Study. Acta Sociol 1976; 19: 227-239.

30. Hayton AC, Allen DG, Scarpello V. Factor Retention Decisions in Exploratory Factor Analysis: a Tutorial on Parallel Analysis. Organ Res Meth 2004; 7: 191-205.

31. R Core Team. R: A Language and Environment for Statistical Computing [Internet]. Vienna, Austria: 2015 [cited 2015 Nov 23]. Available from: http://www.R-project.org 
459 32. Revelle W. psych: Procedures for Psychological, Psychometric, and Personality Research

460 [Internet]. 2015 [cited 2015 Nov 23]. Available from: https://cran.r-

$461 \quad$ project.org/web/packages/psych/psych.pdf

462 33. Deschesnes M, Martin C, Hill AJ. Comprehensive approaches to school health promotion:

463 how to achieve broader implementation. Health Promot Int 2003; 18: 387-396.

464 34. World Health Organization. Promoting health through schools. Report of a WHO Expert 465 Committee on Comprehensive School Health Education and Promotion. WHO Technical $466 \quad$ Report Series 1997; 870:

467 35. Keshavarz N, Nutbeam D, Rowling L, Khavarpour F. Schools as social complex adaptive 468 systems: a new way to understand the challenges of introducing the health promoting 469 schools concept. Soc Sci Med 2010; 70: 1467-1474.

470 36. Mũkoma W, Flisher AJ. Evaluations of health promoting schools: a review of nine studies. $471 \quad$ Health Promot Int 2004; 19: 357-368. 


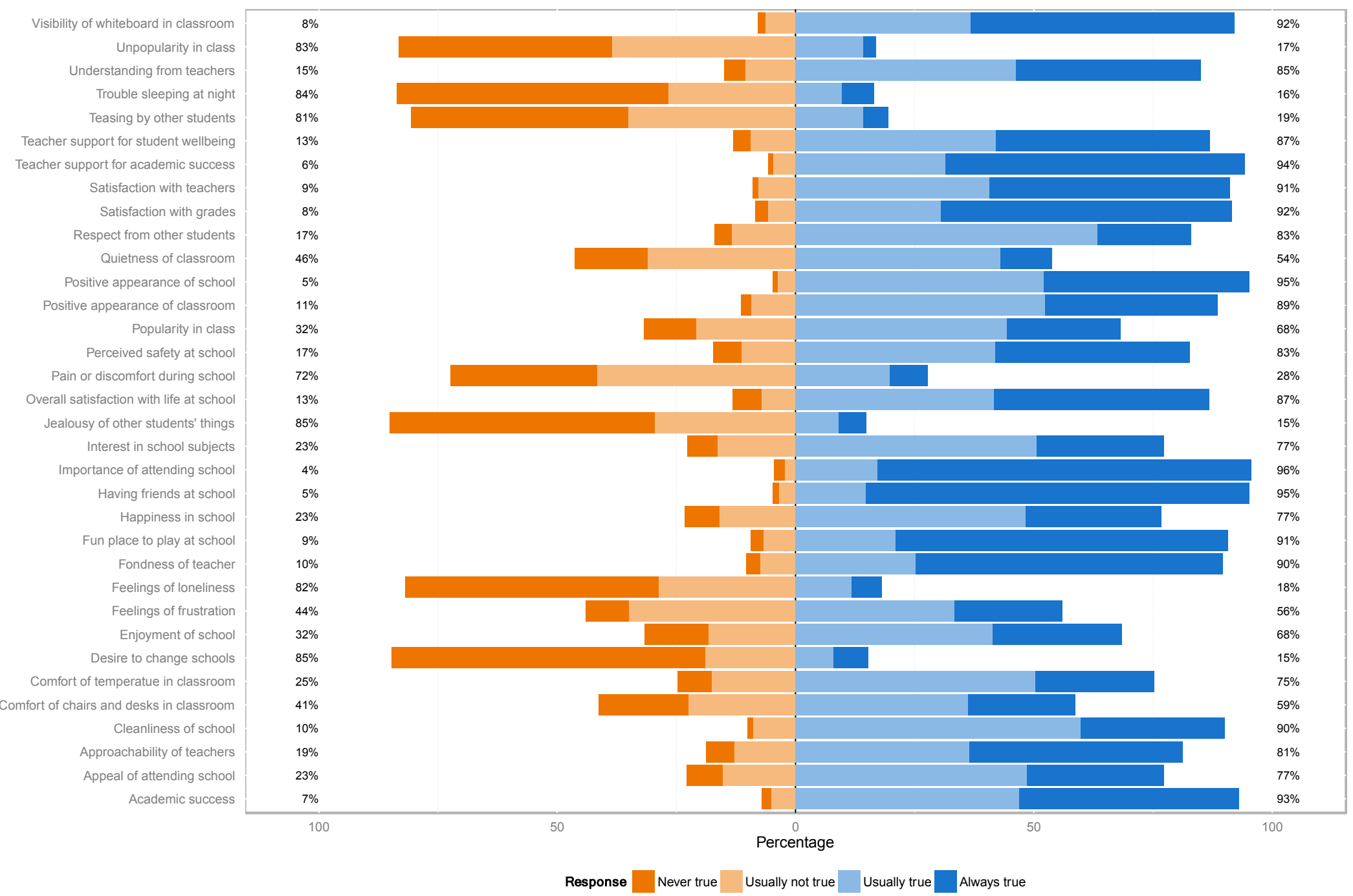

474 Figure 1: Responses to the 37 items on the Quality of Life in School (QoLS) scale $(n=629)$. 


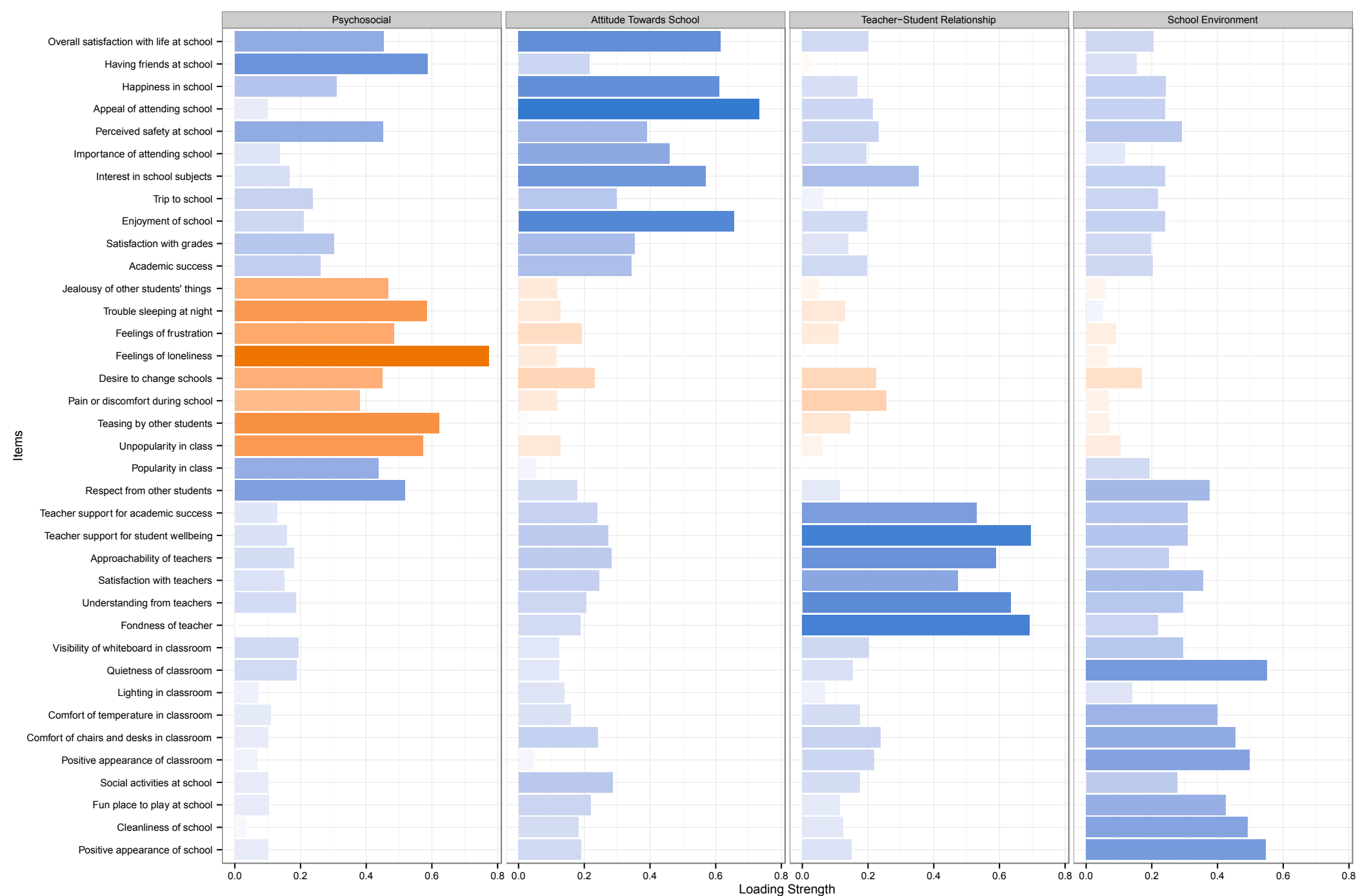

475 Figure 2: Factor loadings for the 37 items on the Quality of Life in School (QoLS) scale. Blue and orange bar colors indicate

476 positive and negative loadings, respectively. Three items with loadings $<0.30$ were dropped from the analysis (Social activities at 


\section{PeerJ}

477 school, Lighting in classroom, Trip to school comfortable) 


\section{TABLES}

479

\begin{tabular}{ll}
\hline & Frequency (n) \\
\hline Male gender & $48 \%(301)$ \\
\hline Grade & \\
4 & $33 \%(209)$ \\
5 & $37 \%(232)$ \\
6 & $30 \%(188)$ \\
\hline Age & \\
9 & $12 \%(77)$ \\
10 & $33 \%(205)$ \\
11 & $31 \%(194)$ \\
12 and older & $24 \%(153)$ \\
\hline Residence & \\
Rural & $65 \%(411)$ \\
Urban & $35 \%(328)$ \\
\hline Household income & \\
Up to $\$ 40,000$ & $27 \%(167)$ \\
\$40,001-\$60,000 & $14 \%(90)$ \\
\$60,001-\$100,000 $\$ 100,000$ & $24 \%(148)$ \\
Missing & $13 \%(82)$ \\
\hline Parental education & $23 \%(142)$ \\
Secondary school or less & \\
College & $26 \%(157)$ \\
University & $49 \%(302)$ \\
Missing & $24 \%(144)$ \\
\hline
\end{tabular}

480

481 Table 1: Socio-demographic characteristics of the study sample $(n=629)$. 


\begin{tabular}{|c|c|c|c|c|c|}
\hline \multirow{2}{*}{\multicolumn{6}{|c|}{ F1 - Psychosocial }} \\
\hline & & & & & \\
\hline Feelings of loneliness & -0.77 & \\
\hline Teasing by other students & -0.62 & & & & \\
\hline Having friends at school & 0.59 & & & & \\
\hline Trouble sleeping at night & -0.59 & & & & \\
\hline Unpopularity in class & -0.57 & & & & \\
\hline Respect from other students & 0.52 & & & & $\mathrm{~F} 4 *$ \\
\hline Feelings of frustration & -0.48 & & & & \\
\hline Jealousy of other students' things & -0.47 & & & & \\
\hline Perceived safety at school & 0.45 & & & & \\
\hline Desire to change schools & -0.45 & & & & \\
\hline Popularity in class & 0.44 & & & & \\
\hline Pain or discomfort during school & -0.38 & & & & \\
\hline \multicolumn{6}{|l|}{ F2 - Attitude towards school } \\
\hline Interest in school subjects & & 0.73 & & & \\
\hline Enjoyment of school & & 0.65 & & & \\
\hline Overall satisfaction with life at school & & 0.62 & & & $\mathrm{~F} 1 *$ \\
\hline Happiness in school & & 0.61 & & & $\mathrm{~F} 1 *$ \\
\hline Interest in school subjects & & 0.57 & & & F3* \\
\hline Importance of attending school & & 0.46 & & & \\
\hline Satisfaction with grades & & 0.35 & & & \\
\hline Academic success & & 0.34 & & & \\
\hline \multicolumn{6}{|l|}{ F3 - Teacher-student relationship } \\
\hline Teacher support for student well-being & & & 0.70 & & $\mathrm{~F} 4 *$ \\
\hline Fondness of teacher & & & 0.69 & & \\
\hline Understanding from teachers & & & 0.63 & & \\
\hline Approachability of teachers & & & 0.59 & & \\
\hline Teacher support for academic success & & & 0.53 & & $\mathrm{~F} 4 *$ \\
\hline Satisfaction with teachers & & & 0.47 & & $\mathrm{~F} 4 *$ \\
\hline \multicolumn{6}{|l|}{ F4 - School environment } \\
\hline Quietness of classroom & & & & 0.55 & \\
\hline Positive appearance of school & & & & 0.55 & \\
\hline Positive appearance of classroom & & & & 0.50 & \\
\hline Cleanliness of school & & & & 0.49 & \\
\hline Comfort of chairs and desks in classroom & & & & 0.45 & \\
\hline Fun place to play at school & & & & 0.43 & \\
\hline Comfort of temperature in classroom & & & & 0.40 & \\
\hline Visibility of whiteboard in classroom & & & & 0.30 & \\
\hline
\end{tabular}

483 Table 2: Factor loadings for the 37 items on the Quality of Life in School (QoLS) scale. Last 484 column on the right indicates lower cross-loadings on other factors. Three items with loadings $<$ 4850.30 were dropped from the analysis (Social activities at school, Lighting in classroom, Trip to 486 school comfortable). 
Score

\begin{tabular}{lrrrrrr}
\cline { 2 - 6 } Domains & Mean (SD) & Minimum & Maximum & Cronbach's Alpha & \% Floor & \% Ceiling \\
\hline Total QoLS & $3.19(0.43)$ & 1.50 & 3.94 & 0.93 & 0 & 0 \\
Psychosocial & $3.15(0.52)$ & 1.17 & 4 & 0.85 & 0 & 0.3 \\
Attitude towards school & $3.20(0.58)$ & 1.12 & 4 & 0.87 & 0 & 6.2 \\
School Environment & $3.11(0.47)$ & 1.38 & 4 & 0.75 & 0 & 1.4 \\
Teacher-students relationship & $3.36(0.59)$ & 1 & 4 & 0.87 & 0.2 & 17.3 \\
\hline
\end{tabular}

488 Table 3: Characteristics of the Quality of Life in School (QoLS) scale in the study sample $(\mathrm{n}=629)$.

489 Abbreviations: SD Standard deviation 


\begin{tabular}{|c|c|c|c|c|c|c|c|c|c|c|c|}
\hline \multirow[t]{2}{*}{ Variable } & \multirow[t]{2}{*}{$\mathbf{n}$} & \multicolumn{2}{|c|}{ Total QoLS } & \multicolumn{2}{|c|}{ Psychosocial } & \multicolumn{2}{|c|}{ Attitude towards school } & \multicolumn{2}{|c|}{ School environment } & \multicolumn{2}{|c|}{$\begin{array}{c}\text { Teacher-student } \\
\text { relationship }\end{array}$} \\
\hline & & Mean (SD) & ES & Mean (SD) & ES & Mean (SD) & ES & Mean (SD) & ES & Mean (SD) & ES \\
\hline \multicolumn{12}{|l|}{ Gender } \\
\hline Female & 328 & $3.22(0.42)$ & Ref & $3.14(0.53)$ & Ref & $3.27(0.54)$ & Ref & $3.15(0.45)$ & Ref & $3.41(0.57)$ & Ref \\
\hline Male & 301 & $3.16(0.45)$ & -0.15 & $3.17(0.52)$ & 0.05 & $3.13(0.61)$ & -0.25 & $3.07(0.49)$ & -0.18 & $3.30(0.61)$ & -0.19 \\
\hline Pvalue & & 0.061 & & 0.577 & & 0.002 & & 0.027 & & 0.018 & \\
\hline \multicolumn{12}{|l|}{ Grade } \\
\hline 4 & 209 & $3.24(0.42)$ & Ref & $3.15(0.53)$ & Ref & $3.24(0.59)$ & Ref & $3.20(0.44)$ & Ref & $3.48(0.52)$ & Ref \\
\hline 5 & 232 & $3.19(0.46)$ & -0.10 & $3.17(0.52)$ & 0.04 & $3.19(0.60)$ & -0.08 & $3.10(0.48)$ & -0.21 & $3.38(0.61)$ & -0.19 \\
\hline 6 & 188 & $3.13(0.42)$ & -0.26 & $3.14(0.52)$ & -0.02 & $3.17(0.53)$ & -0.12 & $3.02(0.47)$ & -0.38 & $3.20(0.60)$ & -0.51 \\
\hline$P$ value & & 0.042 & & 0.815 & & 0.502 & & 0.001 & & $<0.001$ & \\
\hline \multicolumn{12}{|c|}{ Health status } \\
\hline Poor & 0 & - & - & - & - & - & - & - & - & - & - \\
\hline Fair & 32 & $3.04(0.60)$ & Ref & $3.02(0.64)$ & Ref & $2.96(0.83)$ & Ref & $2.99(0.58)$ & Ref & $3.24(0.75)$ & Ref \\
\hline Good & 114 & $3.15(0.44)$ & 0.24 & $3.08(0.53)$ & 0.12 & $3.15(0.64)$ & 0.28 & $3.09(0.46)$ & 0.20 & $3.37(0.59)$ & 0.21 \\
\hline Very good & 250 & $3.21(0.40)$ & 0.41 & $3.19(0.48)$ & 0.35 & $3.23(0.52)$ & 0.49 & $3.11(0.45)$ & 0.26 & $3.36(0.56)$ & 0.20 \\
\hline Excellent & 221 & $3.22(0.42)$ & 0.41 & $3.19(0.53)$ & 0.31 & $3.25(0.53)$ & 0.51 & $3.14(0.46)$ & 0.32 & $3.36(0.61)$ & 0.20 \\
\hline Pvalue & & 0.081 & & 0.097 & & 0.028 & & 0.349 & & 0.719 & \\
\hline \multicolumn{12}{|c|}{$\begin{array}{l}\text { Academic performance } \\
\text { (ELA) }\end{array}$} \\
\hline A & 283 & $3.29(0.37)$ & Ref & $3.26(0.45)$ & Ref & $3.35(0.46)$ & Ref & $3.15(0.43)$ & Ref & $3.45(0.52)$ & Ref \\
\hline B & 232 & $3.10(0.44)$ & -0.46 & $3.10(0.54)$ & -0.33 & $3.06(0.58)$ & -0.57 & $3.05(0.47)$ & -0.22 & $3.24(0.63)$ & -0.37 \\
\hline $\mathrm{C} / \mathrm{D}$ & 50 & $3.09(0.53)$ & -0.49 & $3.02(0.58)$ & -0.51 & $3.05(0.78)$ & -0.58 & $3.04(0.54)$ & -0.23 & $3.37(0.66)$ & -0.15 \\
\hline Pvalue & & $<0.001$ & & $<0.001$ & & $<0.001$ & & 0.041 & & $<0.001$ & \\
\hline \multicolumn{12}{|c|}{$\begin{array}{l}\text { Academic performance } \\
\text { (Math) }\end{array}$} \\
\hline A & 268 & $3.28(0.39)$ & Ref & $3.26(0.48)$ & Ref & $3.32(0.47)$ & Ref & $3.15(0.46)$ & Ref & $3.43(0.51)$ & Ref \\
\hline B & 230 & $3.13(0.43)$ & -0.35 & $3.10(0.53)$ & -0.31 & $3.13(0.60)$ & -0.36 & $3.05(0.45)$ & -0.23 & $3.30(0.63)$ & -0.22 \\
\hline $\mathrm{C} / \mathrm{D}$ & 60 & $3.11(0.50)$ & -0.40 & $3.11(0.52)$ & -0.31 & $3.05(0.72)$ & -0.51 & $3.09(0.50)$ & -0.14 & $3.24(0.70)$ & -0.35 \\
\hline Pvalue & & $<0.001$ & & 0.002 & & $<0.001$ & & 0.047 & & 0.015 & \\
\hline
\end{tabular}

Table 4: Discriminative Validity: Mean scores, standard deviation, effect sizes, and $P$ values across different domains of the Quality of Life in School (QoLS) scale by gender, grade, parent report of child health status, and academic performance in English and Mathematics.

Abbreviations: ELA English Language Arts; Math Mathematics; SD Standard deviation; ES Effect size; Ref Reference category 


\begin{tabular}{l|l|l|l|l|l} 
& Total QoLS & PS & AT & SE & TS \\
\hline Total QoLS & - & 0.83 & 0.86 & 0.76 & 0.78 \\
\hline PS & & - & 0.59 & 0.44 & 0.44 \\
\hline AT & & & - & 0.57 & 0.63 \\
\hline SE & & & & - & 0.61
\end{tabular}

495

496 Table 5: Correlations (Pearson's $r$ ) among different domains of the Quality of Life in School 497 (QoLS) scale.

498 Abbreviations: PS Psychosocial; AT Attitude towards school; SE School environment; TS

499 Teacher-student relationship.

500 